\title{
Evaluation of Pediatric Fingertip Injuries Using Etiology, Demographics and Therapy
}

\author{
(1) Ali Ozgur Karakas, (1) Erkan Yuce \\ Department of Plastic Reconstructive and Aesthetic Surgery, Kirikkale University Faculty of Medicine, Kirikkale Yuksek Ihtisas Hospital, \\ Kirikkale, Turkey
}

\begin{abstract}
Objectives: In this study, 354 pediatric cases were evaluated and treated at the emergency service department due to fingertip injuries in a four years period. The data were studied using etiology, demographics, treatment and complications. This study aims to draw attention to fingertip injuries that are very common in childhood and to help developing preventive strategies.

Methods: Of the 354 patients, 191 were boys and 163 were girls. Their ages ranged from six months to 17 years. These patients were studied concerning sex, injured hand and fingers, injury mechanism, injury zone, selected treatment modalities and complications. All interventions were performed under local anesthesia at the emergency service department. Patients were discharged on the same day.

Results: In our study group, the male patients (54\%) were more affected than the girls (46\%). It was observed that the right hand $(65.3 \%)$ was much more vulnerable to the injury than the left hand $(34.7 \%)$. It was determined that the most injured fingers were middle fingers in the 136 (38.4\%) of the patients, followed by the ring finger (33.9\%). Injury was most frequent at five years old patient group. The most frequent type of injury was crush type injuries with a rate of $83.3 \%$, and among crush type injuries, the most common mechanism was trapping of fingers in the doors or windows. While many of these injuries required surgical intervention, appropriate patients were treated with wound care and secondary wound healing.

Conclusion: In childhood, hand injuries are quite frequent and fingertip injuries constitute the majority of these entities. These childhood injuries lead to significant functional, aesthetic and psychological sequelae in these patients. The knowledge about the etiology, distribution and mechanisms of these injuries will enable the development of preventive measures in this regard. Keywords: Amputation; composite graft; reconstruction; fingertip.

Please cite this article as "Karakas AO, Yuce E. Evaluation of Pediatric Fingertip Injuries Using Etiology, Demographics and Therapy. Med Bull Sisli Etfal Hosp 2020;54(3):306-312".
\end{abstract}

Fis ngertip injuries are common in children, and in various studies, it has been reported that $1.8-2 \%$ of paediatric emergency admissions are hand injuries, and $21-46 \%$ of these are fingertip injuries. ${ }^{[1-3]}$ When the fingertip injuries of adult patients are evaluated, although work accidents are more common etiologically, in pediatric patients, these causes are mostly accidents occurring at home and out- side. In another study, 2\% of all emergency admissions consist of fingertip injuries caused by trapping in the door. ${ }^{[4]}$ In a national study conducted in America, it was reported that finger amputations constitute $91.6 \%$ of all pediatric traumatic amputations. ${ }^{[5]}$ Despite the rapid increase of the child population in our country, there is insufficient information on the epidemiology of this type of injury. Since

Address for correspondence: Erkan Yuce, MD. Kirikkale Yuksek Ihtisas Hastanesi, Plastik Rekonstruktif ve Estetik Cerrahi Klinigi, Kirikkale, Turkey Phone: +90 5302850230 E-mail: drerkanyuce@gmail.com

Submitted Date: July 25, 2018 Accepted Date: July 26, 2018 Available Online Date: September 11, 2020

${ }^{\circ}$ Copyright 2020 by The Medical Bulletin of Sisli Etfal Hospital - Available online at www.sislietfaltip.org

OPEN ACCESS This is an open access article under the CC BY-NC license (http://creativecommons.org/licenses/by-nc/4.0/). 
these injuries vary depending on the activities and regions, the clear determination of the injury patterns will help to form a strategy to prevent these injuries.

It is predictable that organ injuries will continue to their effects on the children's functional and psychological status in their later lives, as children's growth processes continue. The philosophy of fingertip injuries in the development of civilization is beyond the scope of this article, but the presence of articles written in this area shows how important these injuries are. Fingertip injuries bring many difficulties concerning reconstruction due to its unique anatomical structure. However, the main purpose of the reconstruction is attempts to provide fingertip pulp structure, protect the nail bed, and maintain phalanx length.

\section{Methods}

This study was planned retrospectively in the 4-year period (2014-2018) as an evaluation of the records of the pediatric age group fingertip amputations that we intervened in the emergency room. In this study, 354 patients were included and their ages ranged from six months to 17 years. Patients who had one fingertip amputation, who were intervened at the emergency room and candidates for replantation due to Ishikawa's subzone 1 and 2 were not included in this study (Fig. 1). The patients were studied concerning sex, injured hand and fingers, injury mechanism, injury zone, selected treatment modalities and complications. Of the patients, 191 were boys and 163 were girls. Etiological causes were classified as crushing, injury with a play tool, laceration and injury with a working machine. Although injuries with play tools and working machines can be included in a crush- and laceration-type injuries, respectively, they were considered as separate groups as they had specific features. When crush injuries were examined, it was observed that the cause was trapping in the door in 233 cases, and in 66 cases, the cause was crushing injury with stones and similar heavy objects while playing on the street. In 42 cases that were injured with a play tool, the reason was the trapping of the finger in park toys when playing in the playground. When the injury group with laceration was evaluated, it was observed that there were injuries with kitchen tools in nine cases, compression in the bicycle chain in four cases, and cutting with tea cups in one case. Working machine injuries occurred as a result of the stucking of the finger in the sewing machine in three patients. The methods we selected in reconstruction can be classified as skin graft repair (39 patients), composite graft repair (185 patients), $\mathrm{V}-\mathrm{Y}$ advancement flap repair (11 patients), and wound care and secondary healing (119 patients). All interventions were performed under local anesthesia at the emergency service department. While secondary healing is the first

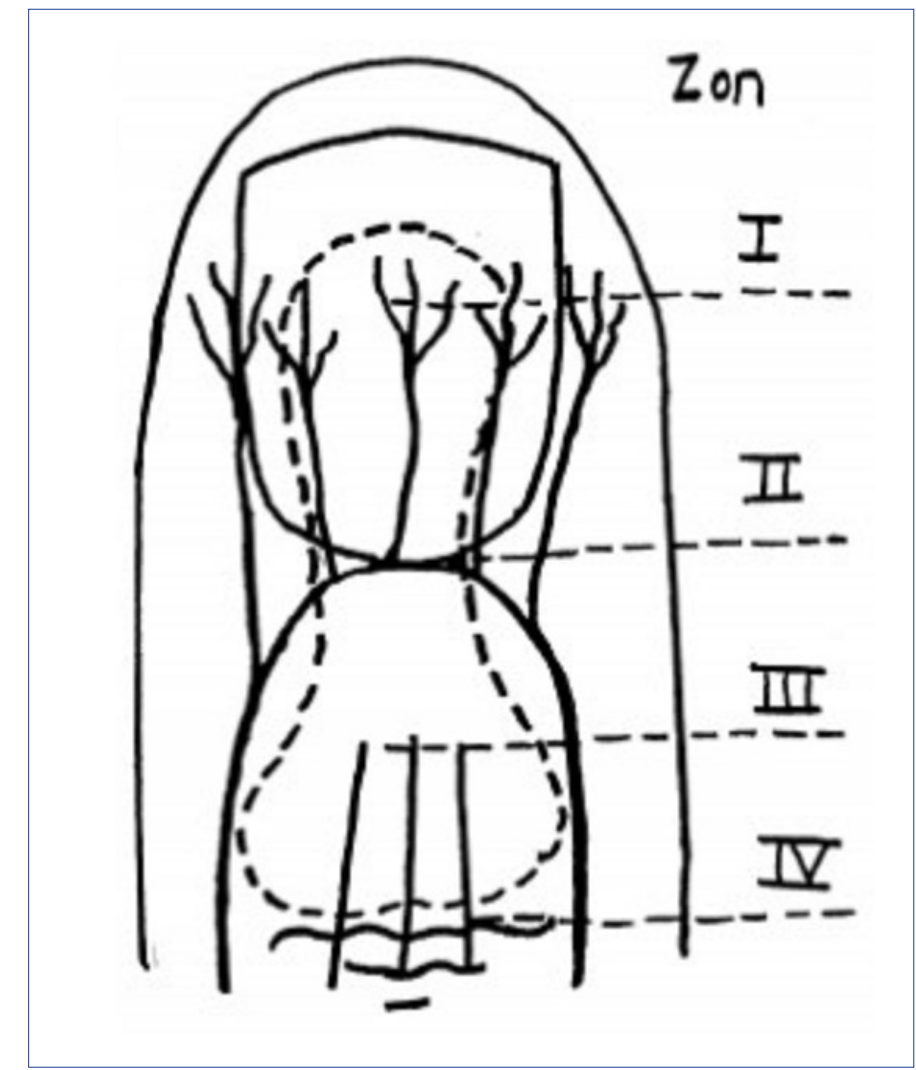

Figure 1. Fingertip zones according to Ishikawa classification.

choice in very distal or superficial defects, V-Y advancement flaps were selected as the primary treatment method in the presence of adequate soft tissue in the exposed bone defects at older ages, and full-thickness skin grafts in wider and deeper defects without exposed bone defects. Composite grafts were seen as the primary treatment option in more proximal and bone-exposed defects in earlier age groups. Complications are classified as infection, skin graft loss and composite graft loss. Partial skin graft necrosis and partial composite graft necrosis were evaluated as successful reconstruction.

\section{Results}

\section{Sex}

During this study, 354 pediatric patients with fingertip amputations were included. Of these, 191 were boys (54\%) and 163 were girls (46\%) (Fig. 2).

\section{Age}

The mean age of the patients included in this study was 5.25 years. Patients were distributed between the ages of 0-17. Injury was most frequent at five years old patient group. This constituted $18.1 \%$ of the total patient group (Fig. 2). 


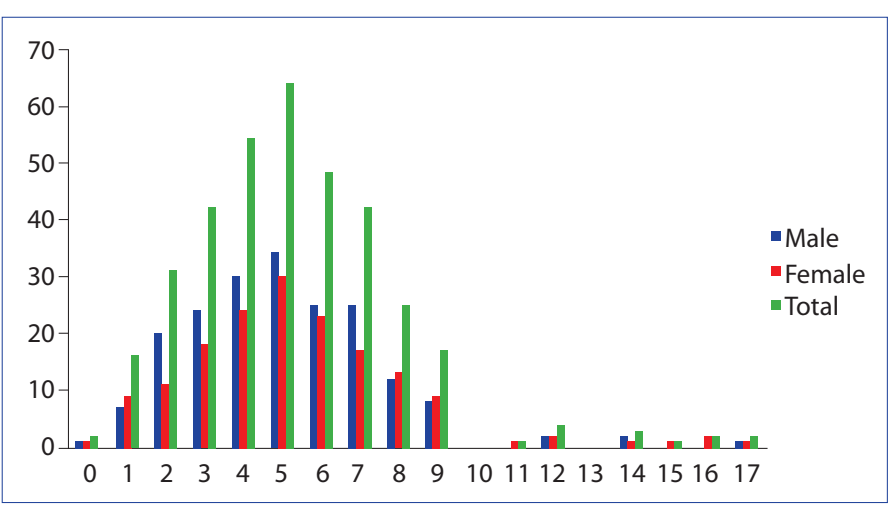

Figure 2. Distribution of patients by age and sex.

\section{Injured Hands and Fingers}

The findings showed that $123(34.7 \%)$ of the patients were injured from the left hand, 231 (65.3\%) of them were injured from the right hand. The most injured finger was a middle finger in 136 patients (38.4\%), followed by the ring finger in 120 patients (33.9\%). The least fingertip injury was seen in the little finger (18\%) (Fig. 3).

\section{Presence of Fingertip Fracture and Injury Zone}

According to Ishikawa classification, 145 (41\%) of the patients had subzone one injury, while 209 of them had subzone two injury ${ }^{[6]}$ In 113 patients, distal phalanx fracture was present along with fingertip injury. These patients make up $32 \%$ of the total patient group.

\section{Injury Mechanism}

Crush injuries are the most common type of injury and were seen in 295 patients. This type of injury accounts for $83.3 \%$ of all patients. Trapping in the door is the most common cause of injury in this group. This is followed by injuries with play tools in the playground and outdoor in 42 patients with a rate of $11.9 \%$, laceration-type injuries with a rate of $4 \%$ (14 patients) and injuries with a working machine (sewing machine) with a rate of $0.8 \%$ (three patients) (Fig. 4).

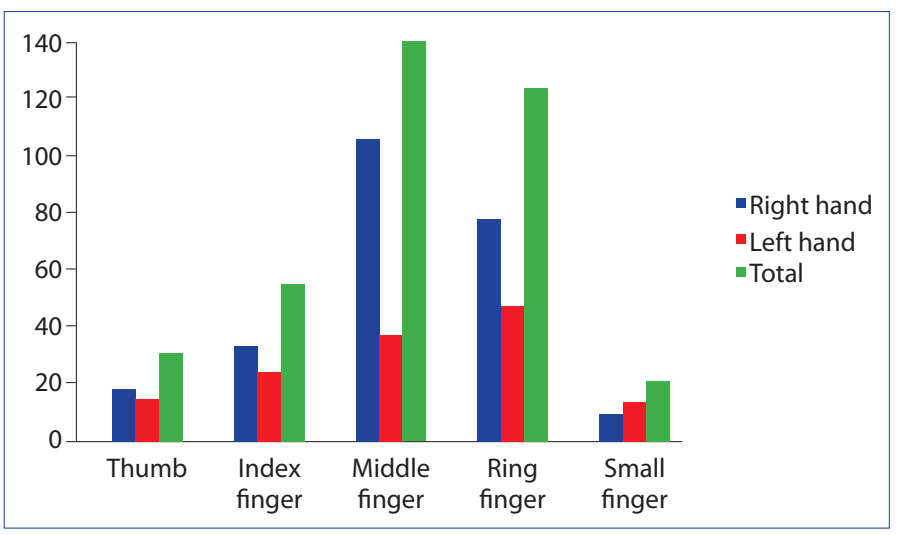

Figure 3. Distribution of injuries by hand side and fingers.

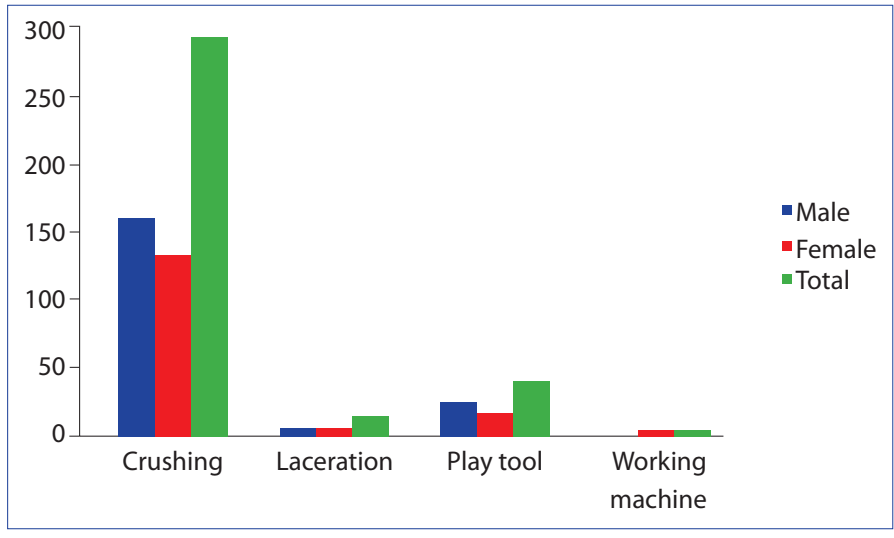

Figure 4. Distribution of hand injury mechanisms by sex.

\section{Treatment Methods}

While 97 (27.4\%) of the patients included in the study admitted to the hospital themselves, 257 (72.6\%) were sent by referral from an external center. All of the patients were treated in the emergency room. Hand $x$-rays of all applicants were obtained. After the first intervention of patients under the digital block, the treatment method was decided. Composite grafts repair was performed in 185 patients $(52.3 \%)$, full-thickness skin graft repair was performed in 39 patients (11\%), and $\mathrm{V}-\mathrm{Y}$ advancement flap repair was used in 11 patients (3.1\%). One hundred nineteen patients (33.6\%) who were decided not to undergo surgery were left to secondary healing (Figs. 5a-c, 6a-b, 7, 8).

$\mathrm{V}-\mathrm{Y}$ advancement flap is used as the first choice if sufficient tissue is available in patients in their late childhood and adolescence. In injuries that did not have enough tissue for the advancement flap, but the bone was not exposed, our second option was repair with full-thickness skin graft. In younger patients, composite graft repair was the first option if the amputate was present and intact. However, if there was no amputate or if the amputate was too damaged to be used, secondary healing was the first option for these patients. In the far distal (subzone 1) tissue loss in all age groups, secondary healing was the preferred treatment method.

\section{Complications and Treatment of Complications}

Complete composite graft loss was observed in 35 of 185 patients who were treated with composite grafts (18.9\%). Partial composite graft losses were not considered as composite graft complications. While 13 patients with sufficient granulation tissue of 35 patients with complete composite graft loss were repaired with full thickness skin grafts, the remaining 22 patients were followed by dressing and left for secondary healing. Graft elimination occurred in five $(12.8 \%)$ of 39 patients repaired with a full thickness skin graft. These patients were also followed up with wound 


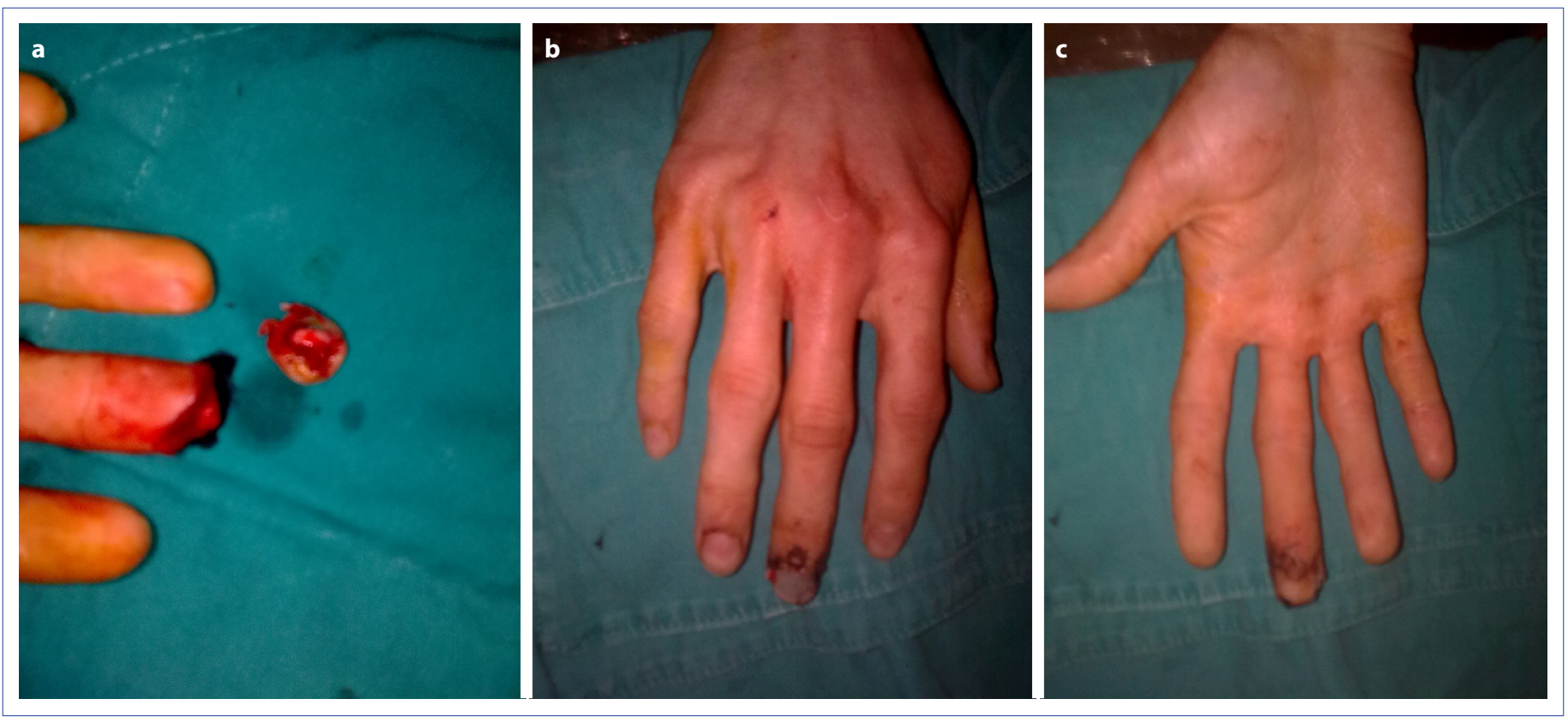

Figure 5 (a-c). The 17-year-old male patient repaired with a composite graft.

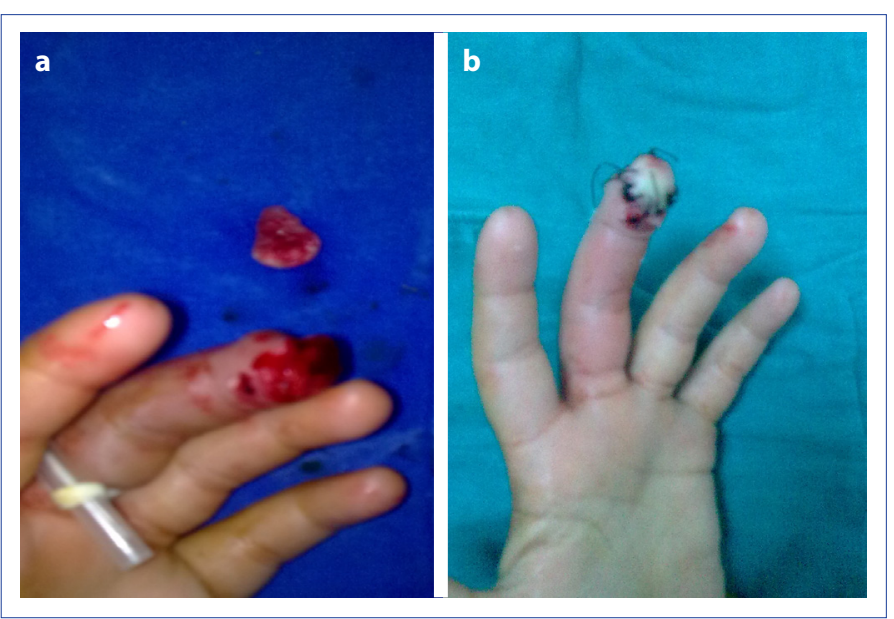

Figure 6 (a-c). The 15-year-old female patient who underwent full-thickness skin graft repair.

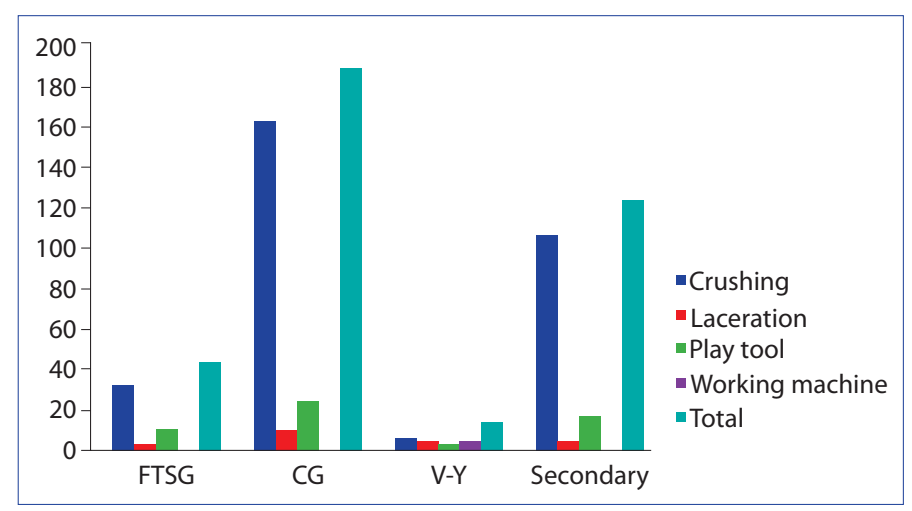

Figure 7. Distribution of treatment methods according to finger injury mechanism. care and left for secondary healing. Wound infection was observed in six (1.7\%) of the patients regardless of the treatment method. Patients were treated with appropriate antibiotherapy and wound care (Fig. 9).

\section{Discussion}

Fingertips are one of the most frequently injured areas of the body. Fingertip amputation seriously affects the patient both functionally and cosmetically. Fingertip amputations are more common in childhood and adolescence. ${ }^{[7,8]}$ Previous studies have shown that pediatric fingertip injuries are more common in boys. ${ }^{[7,9-11]}$ In our study, it was observed that these injuries were more common in boys. Consistent with Bhende et al.'s study, our study also showed that these injuries occur more outside the home. The majority of these hand injuries include blunt trauma, sports injuries, and injuries with sharp objects. Also, in our study, trapping in the door or window leads in the etiology of crush type injuries (295 patients, 83.3\%). This is followed by crushing with blunt objects, trapping with stove cover, especially in winter, injuries with stone or similar hard objects while playing on the street in summer, and this information is compatible with the literature. ${ }^{[7]}$ The interesting part is the injuries that arise from play tools when playing in the playground (42 patients $11.9 \%$ ). The cause of injuries in this way may be design errors in the play tools and require a detailed examination. Leaving children playing outside without supervision by their parents may also be a factor in the occurrence of these injuries. In many studies, the middle finger has been shown to be the most affect- 


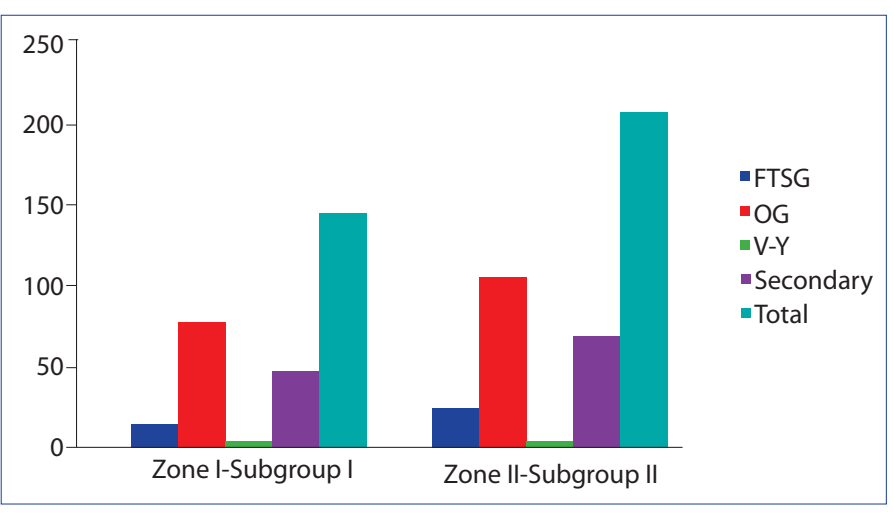

Figure 8. Distribution of treatment methods by injury zone.

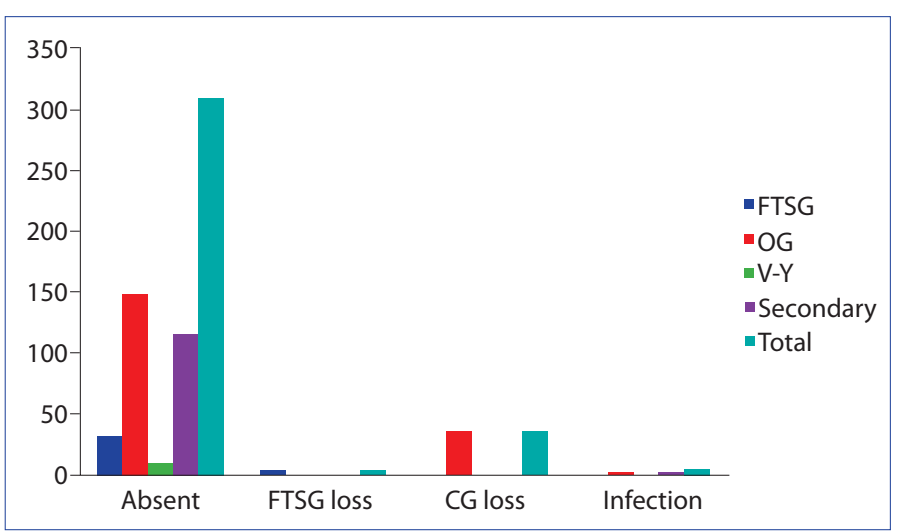

Figure 9. Distribution of complications according to treatment methods.

ed finger in pediatric fingertip injuries with a rate between $25-29 \%$, followed by the $4^{\text {th }}$ finger with a rate of $23 \%$. ${ }^{[1,2,12]}$ In our study, the most frequently injured fingers were the $3^{\text {rd }}$ finger (136 patients, 38.4\%) and $4^{\text {th }}$ finger (120 patients, $33.9 \%$ ), respectively. In addition, five years of age (64 patients, $18.1 \%$ ) was seen as the most frequently injured age. This result may be attributed to that children of this age group are more curious than other age groups and that they interact with all kinds of objects in the environment for learning purposes, but are not aware of their danger. ${ }^{[2,13]}$

In the study of Fetter-Zarzeka et al., in which phalanx fractures were evaluated in fingertip injuries, the fracture rate in distal fingertip amputations was $20 \%$ and was $47 \%$ in the study of Satku et al. ${ }^{[2,14]}$ In our study, distal phalanx fracture was detected in $32 \%$ of patients. There was no significant difference in the distribution of fractures between male and female sexes.

Microanastomosis with microsurgery should generally be the first choice for finger amputation. Replantations at the distal phalanx level in the pediatric patient group have been shown to be more applicable over time with better microsurgical experience and advanced instruments. ${ }^{[15]}$ In our study, replantation was not indicated in our patients, since the level of injuries was on a highly distal (Ishikawa subzone I-II) level. ${ }^{[6]}$

In pediatric hand injuries, the rate of hospitalization in the literature is between 1.3-3.4\%, whereas in our study, no patient was hospitalized. ${ }^{[2,7]}$ All patients were intervened in the emergency room. The reason for this can be that these injuries can be treated under local anesthesia in the emergency room, as well as these injuries require only outpatient follow-up and include no additional life-threatening injuries.

Distal amputations from the nail level are often treated with composite graft application where the pulp and nail bed are anatomically repaired. Some researchers have obtained adequate functional and aesthetic results by turning the amputated part into a full thickness skin graft if the amputation is at a level between the midpoint of the nail bed and the eponychium. ${ }^{[16]}$ The method of repair with composite graft in the fingertip amputations minimizes the loss of the finger length as the patient's own tissue is placed in its place and provides a very good appearance aesthetically. Composite grafting allows defect reconstruction by placing multiple tissues (skin, bone, nail) without vascular anastomosis. ${ }^{[17]}$ Kiuchi et al. reported $100 \%$ success in Ishikawa subzone I and $70.6 \%$ in subzone II with the application of composite grafts in the amputation level Ishikawa subzone I-II. ${ }^{[18]}$ In our study, the total success rate of Ishikawa subzone I-II patients who were treated with composite grafts was $81.1 \%$, consistent with previous studies. Many studies have shown that composite graft applications are more unsuccessful in the adult patient group, and graft viability is less than $50 \%{ }^{[19-21]}$ Therefore, in our study, other treatment options were given priority in older age groups.

In some studies, in cases where there is no distal amputate, it is shown that instead of bone shortening or local flap application, the approach of leaving the fingertip open and closing with semi-occlusive dressings and waiting for result in granulation development by acting as a temporary skin and forming a shape close to the normal pulp. ${ }^{[22]}$ In the study of Halim et al., ${ }^{[23]}$ good functional and aesthetic results were obtained using biological fingertip dressings.

It is contraindicated to leave to secondary healing in larger bone expositions other than small tuft expositions in the distal phalanx. Because as the exposed bone area grows, the risk of bone necrosis and osteomyelitis will be higher than the gain from secondary healing. If it is decided to be left to secondary healing, it has been reported that wound contraction, remodeling and morphological changes in the featured structures due to secondary healing would significantly reduce the success of a latter reconstruction with flap. ${ }^{[24]}$ 
Volar V-Y advancement flap in fingertip amputations was described by Atasoy as volar triangle flap in $1970 .{ }^{[25]}$ In adults, the revascularization of the composite graft is very slow and there is no rapid revascularization to meet the metabolic requirements of the hyponychium and fingertip. Therefore, the flap option should be evaluated in appropriate cases in adults. With this method, a significant amount of tissue can be advanced from the proximal of the pulp to the distal, and the pulp and fingertip tissue defects can be repaired. ${ }^{[26]}$ Sabapathy et al. performed reconstruction with $\mathrm{V}-\mathrm{Y}$ advancement flap in a series of 15 cases in their study. The injuries were located more distally than the nail lunula level. It was reported that the defect was successfully reconstructed in all patients. ${ }^{[27]}$ The most common complication of this type of repairs are permanent sensory changes (paresthesia, hyperesthesia, cold intolerance); infection and necrosis have been rarely reported. ${ }^{[28]}$ In our study, the V-Y advancement flap was performed to patients with older age and less volar tissue loss, and the defect was successfully repaired. No complications, such as necrosis or infection, have been observed.

In a study by Sohn et al. published in 2012, they reported that they repaired the fingertip defects with the full thickness skin graft they obtained from the medial aspect of the big toe under local anesthesia in their series of 16 cases, of which two of them were children. They reported complete graft retention in 13 patients, partial loss in three patients and total loss in one patient. ${ }^{[29]}$ Braun et al. in their study with 100 cases, reported that they repaired 52 patients with fingertip injuries with flaps and 27 patients with partial thickness grafts and that they did not find any significant difference in terms of recovery in patients six and 42 weeks after injury. ${ }^{[30]}$

In our study, 39 patients without bone exposition but deep and extensive soft tissue loss were repaired with full thickness skin grafts, and five of them developed complete loss. Patients with graft loss were followed up by dressing without a new procedure and secondary healing was provided. In our patient groups, no graft was removed from the toe, and the amputation or volar aspect of the wrist was used as a donor area.

\section{Conclusion}

Fingertip injuries bring important functional and aesthetic problems in every age group as well as in the pediatric age group. Although a complete reconstruction cannot be achieved with an ideal repair, near-ideal results are achieved with today's techniques. Paying special attention to fingertip injuries in the pediatric patient group that constitutes our study group will be effective in all areas from psychosocial relationships to the choice of profession in the later life of these patients. The information obtained through such scientific studies will also determine the injury patterns that differ according to the social strata, socioeconomic and geographical regions, and will help in developing strategies to understand these injury mechanisms and prevent injuries.

\section{Disclosures}

Ethics Committee Approval: The study was approved by the Local Ethics Committee.

Peer-review: Externally peer-reviewed.

Conflict of Interest: None declared.

\section{References}

1. Doraiswamy NV, Baig H. Isolated finger injuries in children--incidence and aetiology. Injury 2000;31:571-3.

2. Fetter-Zarzeka A, Joseph MM. Hand and fingertip injuries in children. Pediatr Emerg Care 2002;18:341-5.

3. Ljungberg E, Rosberg HE, Dahlin LB. Hand injuries in young children. J Hand Surg Br 2003;28:376-80.

4. Macgregor DM, Hiscox JA. Fingertip trauma in children from doors. Scott Med J 1999;44:114-5.

5. Hostetler SG, Schwartz L, Shields BJ, Xiang H, Smith GA. Characteristics of pediatric traumatic amputations treated in hospital emergency departments: United States, 1990-2002. Pediatrics. 2005;116(5):e667-74.

6. Ishikawa K, Ogawa Y, Soeda H, Yoshida Y. A new classification of the amputation level for the distal part of the fingers. J Jpn Soc Microsurg 1990;3:54-62.

7. Bhende MS, Dandrea LA, Davis HW. Hand injuries in children presenting to a pediatric emergency department. Ann Emerg Med 1993;22:1519-23.

8. Davis JL, Crick JC. Pediatric hand injuries. Types and general treatment considerations. AORN J 1988;48:237-49.

9. Frazier WH, Miller M, Fox RS, Brand D, Finseth F. Hand injuries: incidence and epidemiology in an emergency service. JACEP 1978;7:265-8.

10. Worlock PH, Stower MJ. The incidence and pattern of hand fractures in children. J Hand Surg Br 1986;11:198-200.

11. Smith ME, Auchincloss JM, Ali MS. Causes and consequences of hand injury. J Hand Surg Br 1985;10:288-92.

12. Claudet I, Toubal K, Carnet C, Rekhroukh H, Zelmat B, Debuisson C, Cahuzac JP. When doors slam, fingers jam!. [Article in French]. Arch Pediatr 2007;14:958-63.

13. Gellman H. Fingertip-nail bed injuries in children: current concepts and controversies of treatment. J Craniofac Surg 2009;20:1033-5.

14. Satku M, Puhaindran ME, Chong AK. Characteristics of Fingertip Injuries in Children in Singapore. Hand Surg 2015;20:410-4.

15. Baker GL, Kleinert JM. Digit replantation in infants and young chil- 
dren: determinants of survival. Plast Reconstr Surg 1994;94:139_ 45.

16. Netscher DT, Meade RA. Reconstruction of fingertip amputations with full-thickness perionychial grafts from the retained part and local flaps. Plast Reconstr Surg 1999;104:1705-12.

17. Alper N, Sood A, Granick MS. Composite graft repair for distal fingertip amputation. Eplasty 2013;13:ic32.

18. Kiuchi T, Shimizu Y, Nagasao T, Ohnishi F, Minabe T, Kishi K. Composite grafting for distal digital amputation with respect to injury type and amputation level. J Plast Surg Hand Surg 2015;49:224-8.

19. Heistein JB, Cook PA. Factors affecting composite graft survival in digital tip amputations. Ann Plast Surg 2003;50:299-303.

20. Lee PK, Ahn ST, Lim P. Replantation of fingertip amputation by using the pocket principle in adults. Plast Reconstr Surg 1999;103:1428-35.

21. Elsahy NI. When to replant a fingertip after its complete amputation. Plast Reconstr Surg 1977;60:14-21.

22. Mennen U, Wiese A. Fingertip injuries management with semi-occlusive dressing. J Hand Surg Br 1993;18:416-22.

23. Halim S, Stone CA, Devaraj VS. The Hyphecan cap: a biological fin- gertip dressing. Injury 1998;29:261-3.

24. Bickel KD, Dosanjh A. Fingertip reconstruction. J Hand Surg Am 2008;33:1417-9.

25. Atasoy E, loakimidis E, Kasdan ML, Kutz JE, Kleinert HE. Reconstruction of the amputated finger tip with a triangular volar flap. A new surgical procedure. J Bone Joint Surg Am 1970;52:921-6.

26. Lemmon JA, Janis JE, Rohrich RJ. Soft-tissue injuries of the fingertip: methods of evaluation and treatment. An algorithmic approach. Plast Reconstr Surg 2008;122:105e-17e.

27. Raja Sabapathy S, Venkatramani H, Bharathi R, Jayachandran S. Reconstruction of finger tip amputations with advancement flap and free nail bed graft. J Hand Surg Br 2002;27:134-8.

28. Jackson EA. The V-Y plasty in the treatment of fingertip amputations. Am Fam Physician 2001;64:455-8.

29. Sohn WI, Jung SN, Kim SW, Kwon H, Im KS. Reconstruction of fingertip defects with great toe pulp grafts. Ann Plast Surg 2012;68:579-82.

30. Braun M, Horton RC, Snelling CF. Fingertip amputation: review of 100 digits. Can J Surga 1985;28:72-5. 